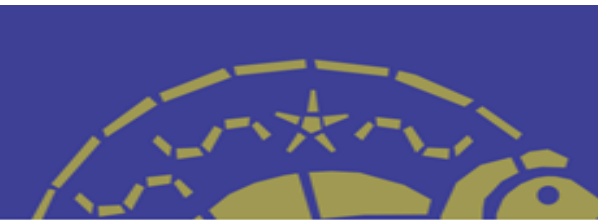

\title{
PRÁTICAS DE FLUIDODINÂMICA COMO INSTRUMENTO DE DIVULGAÇÃO CIENTÍFICA NO ENSINO MÉDIO
}

\author{
Fabiano Tavares da Silva \\ Universidade do Estado do Rio de Janeiro \\ ftavares@iprj.uerj.br
}

\author{
Lamon Benevides de Souza \\ Universidade do Estado do Rio de Janeiro \\ lamonbenevides.eng@gmail.com \\ Leôncio Diógenes Tavares Câmara \\ Universidade do Estado do Rio de Janeiro \\ diogenescamara@gmail.com
}

\section{Resumo}

Este trabalho de extensão foi desenvolvido para aproximar os alunos das escolas públicas da região de Nova Friburgo com o Instituto Politécnico IPRJ/UERJ, proporcionando uma experiência dentro da universidade com práticas de incentivo científico para área de ciências exatas e da terra. Apresentando o universo e diversidade dentro do campo de exatas, com um minicurso voltado para estudos de análise de partículas, viscosidade e permeabilidade, esta iniciativa engloba mais que conhecimentos destas atividades, mas também, o resgate da ligação escola-universidade, inserindo os alunos do ensino médio ao ambiente universitário e em atividades científicas. A importância de fornecer um "norte" para os adolescentes, devido à enorme dificuldade de escolher suas profissões, torna este projeto de extensão uma ferramenta em potencial que, muito provavelmente, irá contribuir para o futuro profissional destes jovens cidadãos. Com isso, além de dar aos alunos uma experiência de práticas laboratoriais também foi possível incentivá-los nos estudos de nível superior, já que eles puderem entender que a universidade está acessível a qualquer cidadão.

Palavras-chave: Divulgação Científica. Fluidodinâmica. Ensino de Ciências. Universidade.

\section{FLUID DYNAMICS PRACTICES AS A SCIENTIFIC DIVULGATION TOOL IN HIGH SCHOOL EDUCATION}

Abstract

This extension project was designed to bring together students from high schools in Nova Friburgo-RJ region with the Instituto Politécnico IPRJ / UERJ, providing an experience within the university with scientific incentive practices to the area of sciences and earth. Introducing the universe and diversity in the mathematics and science area with a short course aimed to studies of particles analysis, viscosity and permeability, this initiative encompasses more than knowledge of these activities, but also restore the link between school and university, inserting the high school students in the university environment and scientific activities. The importance of providing a "north" for teens, due to the great difficulty of choosing their profession, makes this Extension Project a potential tool that will certainly contribute to the professional future of these young citizens. Therefore, the students had a laboratory experience and also it was possible to motivate them to go further in the superior education through the awareness that university is accessible to all of people.

Keywords: Scientific Divulgation. Fluid Dynamics. Science Education. University.

\section{DIVULGACIÓN DE PRÁCTICAS FLUIDODINAMICA COMO INSTRUMENTO CIENTIIFICA EN EDUCACIÓN SECUNDARIA}

\section{Resumen}

Este trabajo de extensión fue desarrollado para aproximar a los estudiantes de las escuelas públicas de la región de Nova Friburgo con el Instituto Politécnico IPRJ / UERJ, proporcionandoles una experiencia dentro de la universidad en las prácticas científicas de las ciencias exactas y de la tierra. Presentar el universo y la diversidad del campo de lãs ciências exactos, con un breve curso dirigido al análisis de los estudios de las partículas, la viscosidad y la permeabilidad, esta iniciativa abarca no solo el conocimiento de estas actividades, sino también el rescate de la relación entre la escuela y la universidad, introduziendo a los estudiantes de lãs escuelas secundarias al ambiente universitario y lãs actividades científicas. La importancia de proporcionar un "norte" para los adolescentes, debido a la enorme dificultad de elegir su profesión, hace que este proyecto de ampliación dé una herramienta potencial que, muy probablemente, va a contribuir al futuro profesional de estos jóvenes ciudadanos. Por lo tanto, además de darles una experiencia de prácticas de laboratório, también pudimos animarles en los estudios de nivel superior, ya que pueden entender que la universidad es accesible a cualquier ciudadano.

Palabras clave: Divulgación Científica. Dinámica de Fluidos. La Educación Científica. Universidad. 


\section{INTRODUÇÃO}

A sociedade do futuro é a sociedade do conhecimento. Durante as últimas décadas o mundo presenciou uma notável ampliação da utilização na produção industrial, além de avanços realizados em diversas esferas do conhecimento científico, especialmente, nas áreas de automação, microeletrônica e informatização. Essa nova onda de inovação, a chamada terceira “revolução industrial”, ocorreu, inicialmente, em um reduzido grupo de Países que estiveram na vanguarda do desenvolvimento científico: os Estados Unidos, o Japão e as principais economias da Europa, tendo, à frente, a Alemanha, e, mais recentemente, a Coréia do Sul e a China (BRASIL, 2012). Acreditando que o incentivo à pesquisa vem antes do ingresso do estudante na universidade, o Laboratório de Fluidos e Fenômenos de Transporte ( $\mathrm{LF}^{2} \mathrm{~T}$ ), do Instituto Politécnico Rio de Janeiro (IPRJ), iniciou o projeto de extensão "Práticas de Fluidodinâmico como divulgação científica para alunos do ensino médio", como forma de incentivar os jovens a seguir nos estudos de forma a buscar um futuro melhor.

A compreensão dos conceitos e princípios do comportamento dos fluidos é fundamental para muitos ramos de aplicação da física. Dessa forma, o escoamento de fluidos em canais e dutos, o conhecimento científico de corpos flutuantes, de máquinas hidráulicas, de sistemas de ventilação e muitos outros assuntos lançam mão das leis de comportamento dos fluidos para obter resultados de aplicação prática.

Este projeto extensionista busca divulgar conhecimentos da área de ciências exatas e da terra, sendo importante ressaltar que o estudo da permeabilidade do solo, como exemplo de um ensaio técnico, é de grande valia para a região, a qual tem relatos históricos de acidentes naturais relacionados a deslizamentos de encostas. Além disso, a cidade e região têm um grande potencial industrial e econômico, principalmente, no campo, sendo uma referência estadual da agroindústria.

O motivo de o público alvo ser estudantes de ensino médio de escolas públicas está ligado ao fato abordado por Marcelo Knobel (ALISSON, 2014), que acredita que a grande massa de estudantes que concluem o ensino médio em escolas públicas não considera o ingresso em universidades públicas. Para desenvolver a integração entre os alunos de ensino médio das escolas públicas e a universidade, foi pensado num projeto extensão que poderia ser realizado no laboratório da própria universidade. "A extensão mostra à comunidade que as universidades não produzem conhecimentos por elas e para elas mesmas, mas sim produzem conhecimentos que são, em sua grande maioria, emergentes das universidades, mas com interface direta com a comunidade" (BAREICHA, 2011). 
"A concepção de que a universidade visualiza atividades de ensino, pesquisa científica e extensão, desempenha um papel fundamental no âmbito da sociedade. Nesse contexto, torna-se imprescindível que o tripé ensino, pesquisa científica e extensão sejam sustentadas pelo princípio da indissociabilidade, ao passo que a conexão entre pesquisa científica e extensão ocorre no momento em que a produção do conhecimento científico é capaz de contribuir para a melhoria das condições qualitativas de vida da população em geral" (SANTOS, 2014).

"O fortalecimento da relação sociedade-universidade proporciona melhoria na qualidade de vida do cidadão, quando ocorre o rompimento das barreiras da sala de aula. A troca de informações deve acontecer entre aquele que está na condição universitária para o que está na condição de aprender. Trata-se de uma passagem de conhecimento. A mudança social é um dos principais objetivos da extensão, que promove melhoria na qualidade de vida das pessoas assistenciadas. Trata-se de um progresso da academia com as comunidades" (RODRIGUEZ et al, 2013).

$\mathrm{Na}$ escolha de qual profissão seguir, os adolescentes se vêem pressionados pela sociedade e por sua própria família. "A dificuldade de escolher uma profissão não é um problema exclusivo do adolescente, já que as decisões profissionais são comuns durante toda a vida do sujeito, considerando, porém, que é na adolescência que essa dificuldade se agrava mais, por ser a primeira vez em que ele se encontra numa situação desse nível, uma vez que escolher uma profissão está diretamente ligado à questão de sobrevivência e que a decisão presente pode acarretar a vida futura” (LARA et al, 2005). Como diz Moura: "Quando quem decide é um adolescente, essa escolha gera mais conflito em função não apenas das dificuldades próprias dessa fase, mas também pelas sérias implicações que a decisão presente pode acarretar no futuro" (MOURA, 2001).

O projeto divulga o universo que existe na área de pesquisa cientifica, destacando a importância do conhecimento sobre fluidodinâmica e a necessidade de bons profissionais da área para o município e região. Nas apresentações são abordados três temas:

$>$ Reologia, que se refere ao ramo da física que estuda a viscosidade, plasticidade, elasticidade e o escoamento da matéria;

$>$ Granulometria, relativo ao estudo e conhecimento do tamanho e distribuição de partículas.

$>$ Permeabilidade, que estuda as características de escoamento de determinado líquido através de um meio poroso.

Estes temas são exemplificados para uma linguagem direcionada ao público alvo, que são alunos de ensino médio, abordando problemas e/ou as situações do dia a dia. 


\section{MATERIAIS E MÉTODOS}

Conforme mencionado anteriormente, o minicurso se baseia em três temas, que são: Granulometria, Reologia e Permeabilidade. Estes temas são apresentados no projetor onde introduzem as aplicações, suas importâncias no mundo da tecnologia e aborda exemplos próximos do dia a dia do aluno (Fig. 1).

O minicurso foi ministrado da seguinte maneira: primeiro foi feita uma apresentação exemplificando sobre a área científica nas universidades e da importância para a sociedade. Em seguida foi feita uma apresentação de cada técnica laboratorial antes dos alunos fazerem cada prática em bancada. As práticas muito técnicas, reologia e granulometria, foram realizadas como práticas assistidas, já a prática de permeabilidade, foram realizadas em bancada pelos alunos, que puderam manipular o equipamento, com cálculos finais da propriedade a partir dos dados obtidos no permeâmetro.

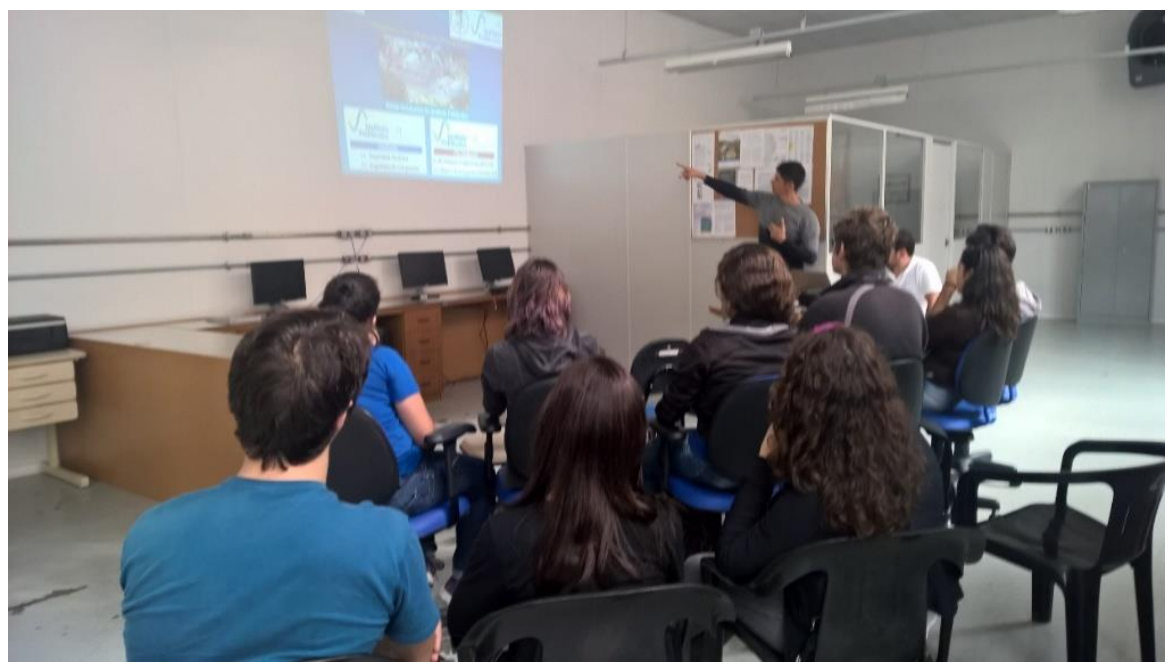

Figura 1 - Apresentação do curso no projetor

A apresentação tem o papel de incentivar os alunos a observarem as tecnologias que os circulam. Nessa etapa são destacados os princípios envolvidos por trás das tecnologias e como elas influenciam na vida do seres humanos. E trazendo também a importância das pesquisas cientificas para o desenvolvimento de novas tecnologias, motivando-os a compreensão que o conhecimento é indispensável na construção de um país desenvolvido.

O cronograma das apresentações, exposições e práticas seguiu a seguinte ordem:

I) Reologia

$\mathrm{Na}$ reologia é apresentado aos alunos, por ser refere ao ramo da física que estuda a viscosidade, plasticidade, elasticidade e o escoamento da matéria. Desta forma, os fluidos, tanto 
no estado líquido quanto no gasoso, podem ser caracterizados por leis que descrevem a variação contínua da taxa ou grau de deformação em função das forças e, conseqüentemente, das tensões aplicadas.

E ainda neste tema, os alunos participam trazendo os exemplos práticos da aplicação, proporcionando uma descontração na apresentação do tema com a participação deles. Alguns ramos de aplicação da reologia são abordados e trazendo sua importância no desenvolvimento de alguns produtos ou processo, por exemplo:

- Controle de qualidade de alimentos, cosméticos, combustíveis, tintas etc;

- Na indústria de petróleo e gás, na manutenção de bombas e tubos. etc;

- Projeto de equipamentos e no processamento dos materiais;

- Análises clínicas como, por exemplo, exame de sangue.

Após a apresentação da reologia e sua importância no dia a dia, os alunos então são convidados para irem à bancada para acompanha como é o funcionamento de um Reômetro e sua utilização (Fig. 2).

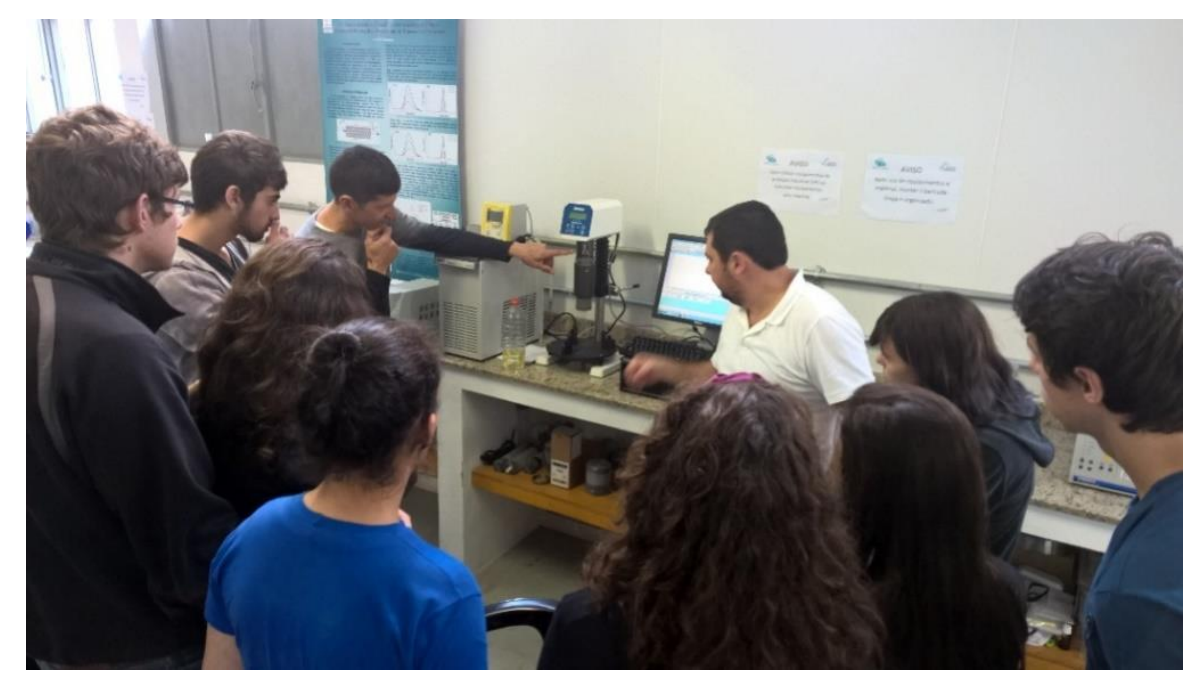

Figura 2 - Experimentação no Reômetro

Os alunos acompanham uma experimentação no Reômetro para desenvolver o aprendizado sobre o estudo de viscosidade. Esse primeiro contato com os instrumentos é importante para o conhecimento, pois falar de viscosidade sem entender como caracterizar um material fica um tanto vago.

II) Granulometria 
Dentre as aplicações pode-se citar a utilização da técnica para caracterização de matérias primas: medidas das distribuições de tamanho de partículas, partículas de tinta usadas em máquinas fotocopiadoras, gotículas produzidas por injetores eletrônicos de combustível, crescimento de cristais, carvão em pó, cosméticos, solos, resinas, compostos farmacêuticos, catalisadores metálicos, materiais eletrônicos, emulsões fotográficas, pigmentos orgânicos e cerâmicos.

Para a caracterização de partículas é apresentado para os alunos o analisador de partículas por difração a laser, que é uma técnica amplamente utilizada para determinação do tamanho de partículas para materiais que vão desde centenas de nanômetros a vários milímetros de tamanho (Fig. 3).

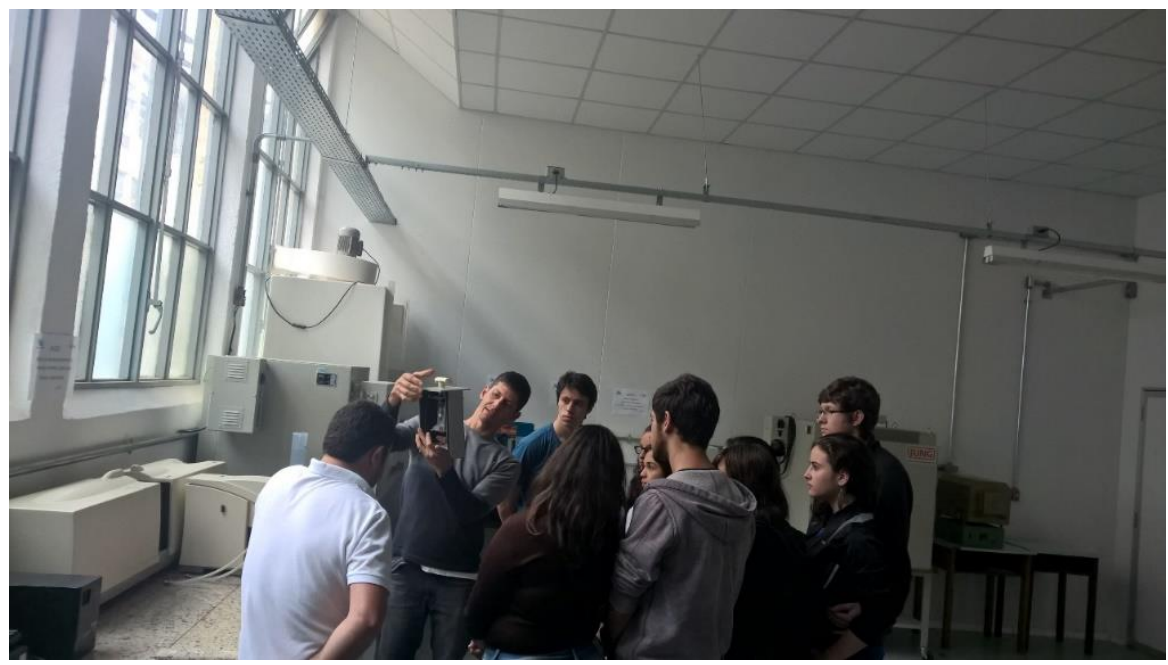

Figura 3 - Apresentação do Analisador de Partículas

Após abordar a importância do estudo de análise de partículas, os alunos são convidados para frente do equipamento que caracteriza uma amostra de partícula e lhes são apresentados os princípios de funcionamento do equipamento e acompanham como se faz uma análise de partículas.

III) Permeabilidade

A permeabilidade é a medida da capacidade de percolação de um fluido através de uma rocha sem alterar (com mais espaços vazios) a sua estrutura interna. Todas as rochas permeáveis podem ser porosas, mas nem todas as rochas porosas são permeáveis, em virtude de os poros não comunicarem entre si ou de serem de tamanho tão pequeno que não permitam a passagem do fluido. 
O permeâmetro foi elaborado no próprio laboratório do IPRJ, esse foi um trabalho em conjunto de alunos do próprio instituto com o professor Diógenes. A prática permeabilidade teve a participação direta dos alunos, tornando este o foco principal do minicurso, uma vez que os alunos puderam fazer as medidas de vazão e obter permeabilidade do leito com cálculos simples. Atualmente, tem-se a implementação de uma unidade de permeabilidade móvel. Após o desenvolvimento, o segundo passo será estender este curso para unidades de ensino que não têm a possibilidade de deslocar seus alunos até o Instituto Politécnico. Assim, poderemos atender melhor a região levando as práticas de fluidodinâmicos até as escolas.

O conhecimento sobre a porosidade e permeabilidade é de grande importância na determinação das características de fluxo dos hidrocarbonetos em reservatórios de petróleo e gás e da água nos aqüíferos.

O permeâmetro é o equipamento utilizado na determinação de permeabilidade de vários tipos de materiais, seja eles consolidados ou não. Quanto maior o valor da permeabilidade, maior a habilidade do material em escoar algum tipo de fluido (Fig. 4).

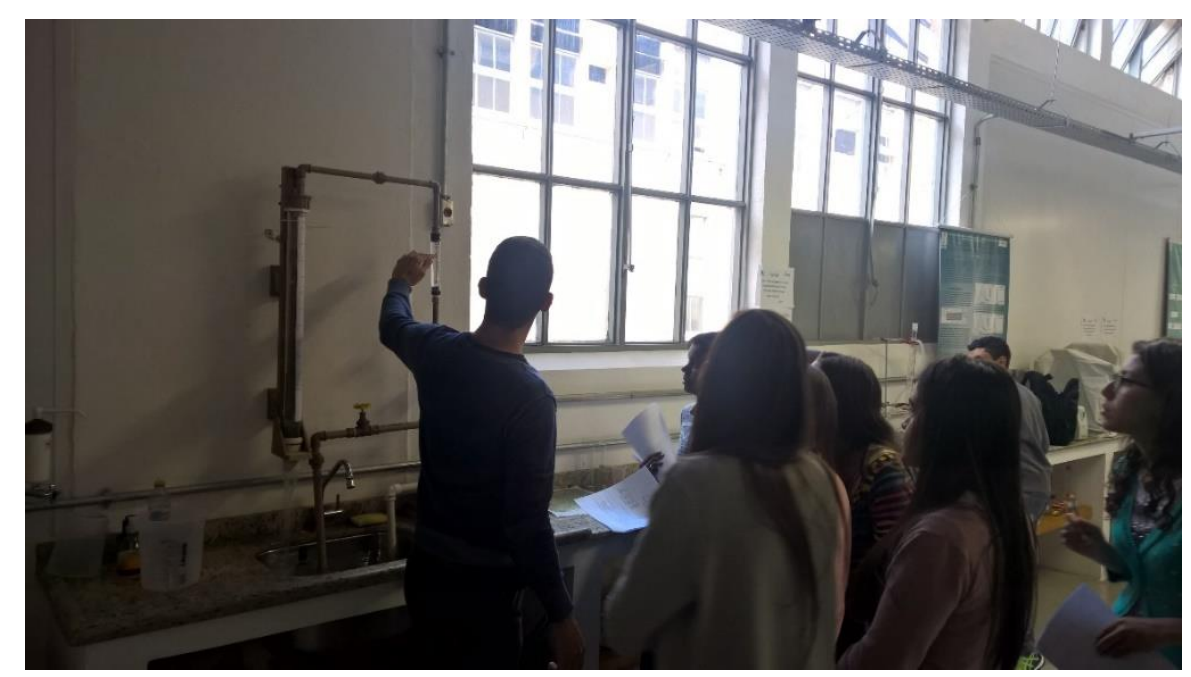

Figura 4 - Explicação do funcionamento do Permeâmetro

O princípio de funcionamento do permeâmetro foi passado para os alunos e diferentes das outras duas práticas, eles puderam manipular o equipamento para obtenção da propriedade (Fig. 5).

Como um béquer, com graduação volumétrica e um cronômetro, eles determinam a vazão em três pressões diferentes. As pressões determinadas pela coluna d'água formada, no tubo transparente, acima do leito poroso. 
A medida de vazão será obtida dividindo o volume de água pelo tempo. Com os dados em mãos, eles traçavam em uma folha milimétrica de pressão versus vazão, uma reta, através da qual era o ângulo de inclinação usado no formulário para obtenção da permeabilidade do leito poroso do permeâmetro (Fig. 6).

Através dessa prática os alunos tiveram um maior contato experimental em laboratório, que de certa forma é importante na compreensão de fenômenos vistos no ensino médio.

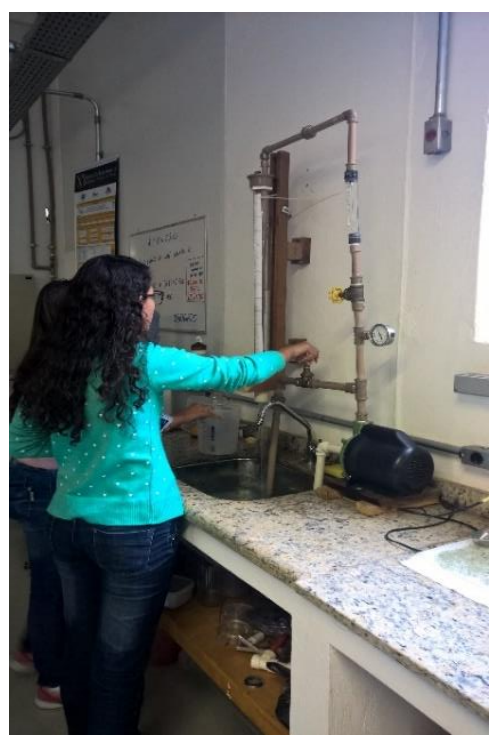

Figura 5 - Experimento feito pelos alunos

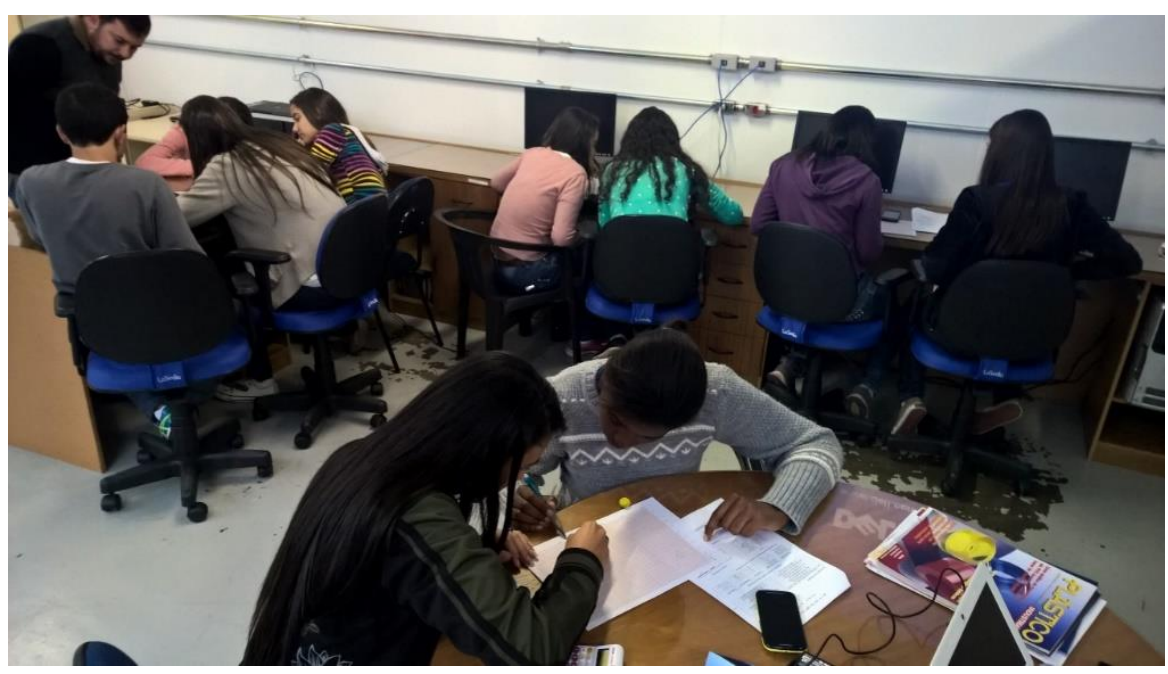

Figura 6 - Obtendo o ângulo de inclinação da reta, obtido através de práticas feitas 


\section{RESULTADOS E ANÁLISES}

A interação dos alunos e professor fez com que as aulas e as práticas fossem dinâmicas, trazendo então a atenção e dúvidas a respeito dos temas abordados; isso veio a suprir as expectativas tanto dos organizadores quanto das participantes.

O projeto apresentou o resultado esperado, uma vez que se conseguiu que o público alvo tivesse o contato com ás práticas na área de ciências exatas e da terra. As curiosidades dos alunos contribuíram com o objetivo do curso e todos participaram dos experimentos.

Os conhecimentos adquiridos pelos alunos do ensino médio foram importantes, dúvidas foram sanadas e, principalmente, pelo fato de estarem no ensino médio, tiveram o contato com ás práticas na área de ciências exatas e da terra. Com isso, tiveram contato com alguns princípios de exploração de petróleo, desenvolvimentos de tecnologias, pesquisas científicas e algumas técnicas de caracterização.

O desenvolvimento da integração do Instituto Politécnico da UERJ com escolas públicas do município fortalece as atividades de educação na região o que possibilita um maior acesso desses alunos na universidade. Desenfronhar, para os alunos de ensino médio que é uma universidade pública, é uma maneira de mostrar a grandeza do ensino superior e o quanto pode contribuir para a formação profissional e intelectual.

O projeto apresentou significativos resultados que puderam ser observados pela motivação e curiosidade sobre o tema, e atenção dos alunos nas atividades e também no encerramento do curso com a entrega dos diplomas de participação.

No final do mini curso os alunos recebem um certificado de participação, com o título, "Práticas de Fluidodinâmico como incentivo científico para alunos do ensino médio de escola públicas do estado do Rio de Janeiro”, no qual constava uma carga horária de 4 horas (Fig. 7).

O Colégio Estadual Tuffy El Jaick foi o primeiro colégio a participar do trabalho, com o envio de duas turmas do terceiro ano do ensino médio, com um total de 20 alunos. 


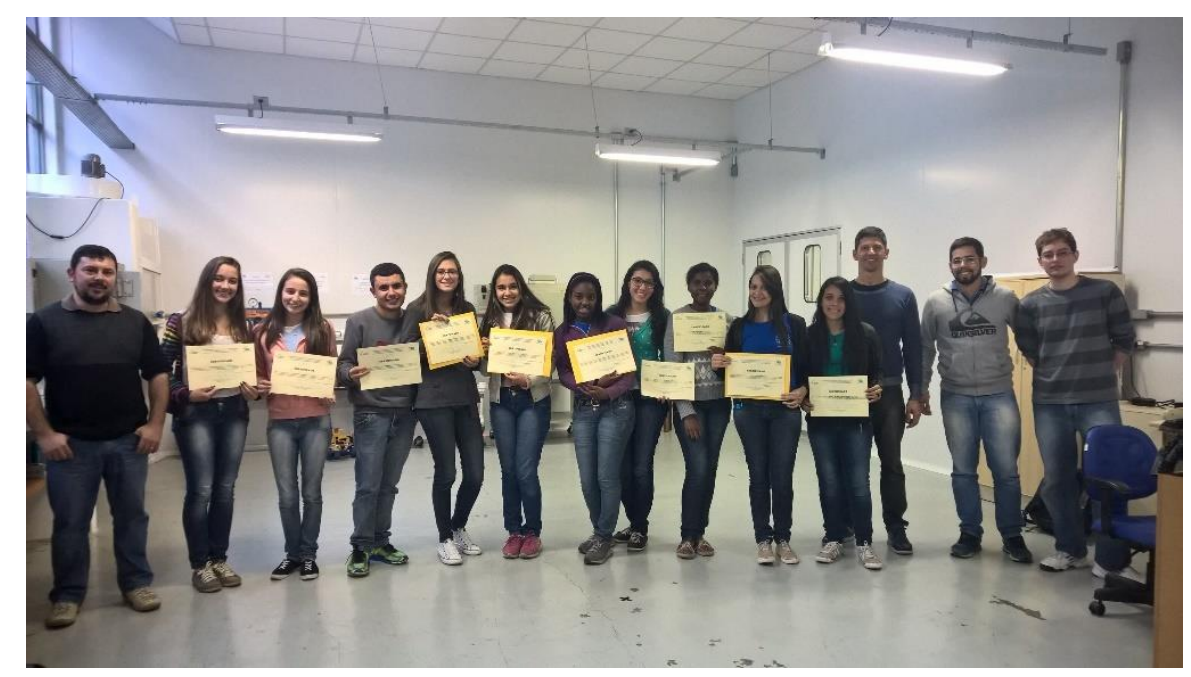

Figura 7 - Entrega dos Certificados ao final do minicurso

Os participantes, ao final do minicurso, tiveram um momento de informações de como ingressar numa universidade pública, como funciona o sistema de cotas e os desafios na hora de prestar um vestibular. Também, houve aqueles que gostariam de saber como é a experiência do ambiente universitário.

\section{CONSIDERAÇÕES FINAIS}

O desenvolvimento da integração do Instituto Politécnico da UERJ com escolas públicas do município fortalece as atividades de educação na região o que possibilita um maior acesso desses alunos na universidade.

A chance de estar no ambiente universitário, com atividades práticas na área de tecnologia e ciência, proporcionou uma experiência para os participantes, notando também o interesse deles por informações dos meios de ingresso no ensino superior nos cursos prestados pelo IPRJ. Este é um feedback que esperávamos pois, com isso, percebe-se que a divulgação cientifica é importante para fomentar novos pesquisadores na área de Fluidodinâmica.

Este projeto está sendo novo para o instituto, pois de maneira indireta estamos não só influenciando os alunos à imersão numa universidade, mas trabalhando nos docentes a importância de se desenvolver a comunicação universidade-escola.

A originalidade do trabalho feito trouxe com ele desafios no desenvolvimento da literatura e na implementação do minicurso. No projeto estão sendo disponibilizados instrumentos científicos que dificilmente terão contato no ensino médio, trazendo para os participantes a ambientação com a tecnologia e sua importância na pesquisa. 
O desafio, dos próximos encontros, é a implementação de um questionário objetivo, para se obter o feedback dos participantes sobre a satisfação, conhecimento agregado no curso de extensão e possíveis melhorias na dinâmica dos experimentos.

\section{REFERÊNCIAS}

ALISSON, Elton. Jornalistas da Agência Fapesp. A grande massa de estudantes que concluem o ensino médio em escolas públicas não considera o ingresso em universidades públicas. Revista eletrônica Unicamp, São Paulo, 07 fev. 2014. Disponível em: $<$ https://www.revistaensinosuperior.gr.unicamp.br/reportagens $>$, Acesso em: 22 de agosto de 2015.

BAREICHA, Paulo; ALVES, Fernando A. Teatro Ecopedagógico: Ensino, Pesquisa e Extensão. $3^{\circ}$ Congresso Internacional de Educação. 2011, acesso em julho de 2015.

BRASIL.Ministério da Ciência, Tecnologia e Inovação (MCTI). Estratégia Nacional de Ciência, Tecnologia e Inovação 2012 - 2015.1. Ed. Brasília: MCTI, 2012. v.9.

LARA, L.D.; ARAÚJO, M.C.S.; LINDNER, V.; SANTOS, V.P.L.S.O Adolescente E A Escolha Profissional: Compreendendo O Processo De Decisão. Arq. Ciênc. Saúde Unipar, Umuarama, 9(1), jan./abr. p.57-61, 2005.

MOURA, C.B. de, Orientação Profissional: Sob O Enfoque Da Análise Do Comportamento. Londrina: UEL; 2001.

RODRIGUES, A. L. L., PRATA, M. S., BATALHA, T. B. S., COSTA, C. L. N. A., NETO, I. F. P. Cadernos de Graduação - Ciências Humanas e Sociais, Aracaju, v. 1 n.16 p. 141-148 mar. 2013.

SANTOS, M.P. Extensio: R. Eletr. de Extensão, ISSN 1807-0221 Florianópolis, v. 11, n. 18, p. 36-52, 2014. 